\title{
Herbicide Reduction Methods
}

\author{
Martin Weis, Martina Keller and Victor Rueda Ayala \\ University of Hohenheim \\ Germany
}

\section{Introduction}

\subsection{The necessity for weed management}

Weed control is crucial to prevent high yield losses. Oerke estimated the potential yield loss of weeds rising up to $34 \%$ worldwide (Oerke, 2006). Chemical weed control with herbicides has been the major control tool for the last decades in developed countries.

These management practices have proven to be useful, effective and worth the efforts for many farmers, but chemical weed control in the long term has to face changing conditions and circumstances. They are used in a constantly changing and adaptive environment, and therefore their effectiveness can vary over time and location. However, the extensive and unsound use of herbicide has resulted in the development of herbicide resistance in several weeds. In addition the launch of herbicides with new modes of action has slowed down considerably (Rueegg et al., 2007). This can partly be ascribed to the consolidation process of the agrochemical industry resulting in less overall research and development infrastructure as in the increased regulatory requirements for registration. In Europe, the review process of pesticides under the Directive 91/414/EEC has additionally narrowed the spectrum of approved herbicidal active ingredients.

Apart from the positive effect by eliminating weed competition, herbicides can have a negative impact on the environment. Today, traces of herbicides can easily be found in surface and ground water. Public concerns due to these negative side-effects have led to political action plans to reduce herbicide use, especially in Europe these considerations are taken to a large geographic scale.

Thus strategical needs for resistance management and the smart use of the existing and remaining herbicides in combination with other weed management tools will be crucial to keep these weed control tools viable for further use. Also political pressure requires to rethink the use of herbicides and to promote integrated weed management systems. Therefore, the aim of this book chapter is to present ways and options to reduce, complement and replace herbicides.

\subsection{Political framework}

In the European Union new guidelines are being defined for integrated pest management (IPM) (European Parliament \& Council of the EU, 2009, Article 14(5)). As part of the new regulations, the weed management and proper herbicide use are to be reconsidered and put into practice from the year 2014 onwards. The European guideline will be transcribed 
into national law to that date. The general policy of IPM is defined by the following steps (Zornbach, 2011)

I. preventive management of pests

II. monitoring

III. control decision

IV. preference for non-chemical methods

V. pesticide selection

VI. reduction of pesticides to the necessary amount

VII. resistance management

VIII. monitoring of treatment success

This procedure will be also mandatory for the application of herbicides. The explicit statement to prefer non-chemical management methods and to reduce the amount of herbicides demands for new methods in weed management approaches. The possible improvements range from the development of information technologies for decision support to new implements for site-specific herbicide usage or alternative weeding methods. On the European and national level research activities are funded to develop technologies supporting this policy, e.g. within the ENDURE and PURE projects (Pesticide Use-and-risk Reduction in European farming systems with Integrated Pest Management) and on national level there are initiatives to develop new practises, e.g. in Germany the innovation funding program of the German Federal Agency for Agriculture and Food (BLE - Bundesanstalt für Landwirtschaft und Ernährung). Some of the research efforts, leading to technology supporting the new policy, will be outlined in this chapter.

\section{Integrated weed management}

Integrated weed management (IWM) is one part of integrated pest management (IPM), the latter targeting at all pests occuring in crops. The European research network ENDURE defines IPM as:

IPM is a sustainable approach to managing pests by combining biological, cultural and chemical tools in a way that minimises economic, environmental and health risks.

Integrated weed management combines all applicable methods to reduce the effect of weeds in the cropping systems. The general goal of IWM is to enhance the weed management by using different methods to reduce the weed pressure. Swanton et al. (2008) illustrate the approach as "use of many little hammers". Synergistic effects are expected, leading to higher overall success rates in weed management than using only one of the weed suppressing measures. The combination of different methods has the advantage, that the overall effect can lead to a better weed suppression not only in one growing period, but also over larger time scales. Since many of the methods are 'orthogonal', in the sense that they are not depending on each other and work with different modes of action, a combination of these can add up the effects of the treatments. Weed management happens to be carried out in constantly changing conditions: depending on the weather conditions, concurrence situation (e.g. according to the crop type and rotation), weed pressure, seed bank, the weeds biological properties and herbicide resistance status, some measures may be more effective than others. A long-term strategy has to take into account the changes of the weed population and of the influencing environmental factors. Weeds, like any biological entity, can adapt to changes 
in their environment. Such changes can be human-induced or general, environmental ones (climatic shifts, newly introduced species).

Crop rotation is a classical technique with a weed suppressing effect, widely adopted in the agricultural practise. It can disturb the regeneration cycle and accumulation of weeds, leading to lower infestation densities of the crop relevant weed species over the years. Weed management depends on the cropping system to which it is applied, since the cropping system can have a significant influence on the weed pressure. Recent precision farming technology may lead to a wider adoption of different cropping systems: Corre-Hellou et al. (2011) compared weed suppression for cereal-pea intercropping systems and found a significant reduction of weeds compared to sole pea crops. The wider application of intercropping is supported by precisely working equipment, supporting the management starting from the sowing until harvest with improved methods for the planning, treatment, monitoring and harvest.

An reintroduction of cover crops, which have not been used intensively in the last decades, also exhibits unused weed-supressing potential (Blackshaw et al., 2001). Undersown species can suppress the weeds due to their allelopathical effects or by early coverage, preventing germination and providing competition.

Sowing time, sowing rates and row spacing are closely related to the crop type and management practises, and all have an influence on the weed development and should be optimised to reach low weed infestation levels. A long-term strategy should include the prevention of seed set and distribution of weed seeds. The measures range from tillage and harvesting operations within the field to contamination prevention of seeds for sowing. An accumulation of weed seeds in seed banks needs to be addressed, at least certain levels of seed and resulting weed density should be avoided.

Swanton et al. (2008) identifies four key components for IWM management: i) tillage (depth, soil type) and its influence on vertical weed seed distribution. With reduced tillage practices like no-tillage and strip-tillage seeds are close to the surface and are subject to predation and a more uniform emergence, and rotational tillage is considerable. ii) time of weed emergence, relative to the crop and the iii) critical period for weed control, both relevant for the yield effect of the weeds on the crop have to be taken into account for optimised management decisions. iv) Weed germination during the harvest window, after the critical period, can affect yield quality and the harvesting operation, but are not regarded to be an issue for the seed bank development.

The adoption of IWM practices by the farmers has two aspects: one the one hand most farmers are aware of the implications and use one or more of the techniques affecting the weed distribution. On the other hand such measures are usually not practised as conceptual long-term strategy, and the benefits and problems are not perceived as levelling out over time. Often the most effective, chemical solution is preferred to achieve a "clean acre", as long as there are no obstacles like herbicide resistance.

The introduction of IWM into the practise therefore requires training efforts on the farmers side. Risks for the several options should be assessed and modelled in expert systems, which then can aid consultants and farmers in their decision-making.

Llewellyn \& Pannell (2009) studied the perception and adoption of knowledge about IWM techniques and resistance development by farmers through workshops. They found 
significant changes in workshop participants behaviour and their intention to extend practices to different weed management methods. In Australia training and information resources were created to help farmers and advisors implement integrated weed management according to a manual (Storrie et al., 2006).

Jones et al. (2006) created a risk model for alternative weed management and found seasonal variability to have a substantive influence on the accuracy of the risk assessment and the estimation of the benefits. According to case studies conducted by the ENDURE network in maize crops (ENDURE, 2008), comparable weed control can be achieved with different levels of IWM, concluding that a reduction of herbicides apparently has a proportional manner: the more non-chemical measures are added the more can herbicide input be lowered. Models have been created to tackle complex interaction of the components for a sustainability analysis of management systems, including measures for weed management (ENDURE, 2009).

\section{Alternative weed management without herbicides}

There are several methods to control weeds without herbicides. It is well known that conventional farming heavily depends on herbicides for weed control, therefore most alternative measures are developed and used in ecological farming. Perhaps, only preventive methods such as soil tillage and seed bed preparation are used in both, conventional and organic farming (Bond et al., 2003; Rueda et al., 2010). In the previous section it was stated that the necessary weed management should be a balanced approach by including many different measures to successfully reduce weed pressure, towards an integral management plan. This procedure is applicable to both, conventional and organic, farming systems. Combination of many measures has the advantage that weed control can be extended throughout the whole crop growing period and also in large scales, and due to many modes of action the risk of resistant species will severely decrease. Several modes of action can be distinguished to control weeds without herbicides: burial of weeds in soil, cutting plants into pieces, uprooting, rupture of the plant cell and desiccation, etc. which are described below.

If plants are uprooted, they loose proper soil contact, disrupting their supply of water and nutritions. Destroying or disturbing the function of leafs or stems lead to a delayed development or death. Some methods target the seeds in the soil, disturbing their ability to develop into plants and thereby reducing the germination probability. Tools to achieve this are mechanical or use heat, applied either through flame, electrocution (Blasco et al., 2002) or laser light (Heisel et al., 2001; Nadimi et al., 2009).

\subsection{Mechanical weeding (harrowing)}

Mechanical weed control is referred to as cultivating tillage, because it mostly comprises a shallow soil cultivation after sowing or planting with tools such as harrows and hoes (Rueda et al., 2010). These tools can be used to perform a whole crop cultivation (crop and weed plants), inter-row and intra-row cultivation. Cultivating tillage mainly controls annual weeds through uprooting, tearing plants into pieces and burial of weeds into soil; however perennial weeds are little affected (Jensen et al., 2004; Kurstjens \& Kropff, 2001; Kurstjens \& Perdok, 2000; Rueda et al., 2010). Since controlling weeds with mechanical tools generally is a trade-off between weed control and crop damage due to cultivation, post-emergence cultivation must be combined with pre-emergence methods to overcome the poor selectivity (Melander et al., 2005). Cultivating tools like harrows and hoes may be used for cultivating row crops, and also 
small grain cereals or legumes (Jensen et al., 2004; van der Weide et al., 2008). Weed harrowing is carried out on the whole crop area and hoeing is applied inter-row, however, crop plants may also be affected (Melander et al., 2005).

Weed control by mechanical means has generally a lower efficacy than herbicides, therefore the challenge is to improve mechanical weeding to make it competitive with chemical control. Five experiments on weed harrowing in winter wheat (Triticum aestivum L.) were carried out in Denmark and Germany, aiming to increase the cultivation selectivity and weed control efficacy while reducing the crop damage by soil coverage, as a result of harrowing (Rueda-Ayala et al., 2011). Three of the experiments were kept weed free either with herbicides or due to lack of natural weed germination. These experiments were also harrowed to measure crop tolerance to soil cultivation and thus burial in soil. Two experiments were only harrowed, in order to control weeds and calculate the highest achievable yield as a consequence of weed control by harrowing. At each location, there were at least one weed free experiment and one experiment with high weed competition in the same field, to compare weed control and crop tolerance to harrowing. Four intensity levels in Denmark and five in Germany were created by increasing the number of passes with the spring-tine harrow on the same day of cultivation, an untreated control was included in any case. The most dominant weed species were Veronica persica $(47 \%)$, Viola arvensis $(31 \%)$, Poa annua $(8 \%)$, and Chenopodium album (7\%), in Denmark, and Matricaria inodora (65\%), Cirsium arvense (16\%), Alopecurus myosuroides (10\%), and Galium aparine (6\%) in Germany.

The selectivity of harrowing was a bit higher in Denmark than in Germany, although the crop growth stage at the time of harrowing was irrelevant for the selectivity. The first pass with the harrow controlled $93 \%$ and $68 \%$ of the weeds in Denmark and Germany, respectively. Likewise, four passes controlled $97 \%$ and $98 \%$ in Denmark and Germany, respectively. In order to achieve $80 \%$ weed control, it was required to achieve about 2 to $12 \%$ soil cover in Denmark and about 22 to $30 \%$ soil cover in Germany. The crop yield loss by $25 \%$ soil covering as a result of harrowing was about 0 to $5 \%$ in Denmark and 0 to $1 \%$ in Germany. When comparing the uncultivated plots with the herbicide-treated plots, it was found that the effectiveness of weed harrowing was comparable to the herbicide treatment. The average crop yield gain by harrowing with an optimal intensity in Denmark was 13\%, which was not different from the $14 \%$ yield gain obtained by weed control with herbicides. In Germany it was not possible to measure the effect of herbicides, due to lack of natural weed germination, however, the average yield gain obtained by controlling weeds due to harrowing was as high as $27 \%$. These results are a proof that weed harrowing is a very effective tool to control weeds, and under favourable soil conditions, applying the optimal intensity and at the right crop growth stage, these benefits are comparable with those obtained with herbicides.

\subsection{Thermal weeding, flame weeding, manual weeding}

While mechanical weed control is the most widely used non-chemical weed control method in arable crops, there are also other means to reduce the amount of weeds. Although the latter are often applied to control weeds in non-arable areas, e.g. on roads or rails, these can nevertheless be used for farming, too. Especially in high-value crops these can be considered, even though the measures may be accompanied by a higher energy, material or labour input. 


\subsubsection{Soil solarisation, soil steaming, and hot water}

Soil solarisation achieves dis-infestation of soil due to the heat resulting from trapped soil radiation by covering the moist soil with a plastic film during several weeks, which has the consequence of killing soil-borne pathogens and to avoid weed seed germination by thermal inactivation (Candido et al., 2011; Cimen et al., 2010). This technique, alone or combined with other techniques, has been found to effectively control weeds like green bristlegrass (Setaria viridis), common purslane (Portulaca oleracea), redroot amaranth (Amaranthus retroflexus), bindweed (Convolvulus spp), black night-shade (Solanum nigrum), canadian thistle (Cirsium arvense), and even weed species unsusceptible to selective herbicides (Candido et al., 2011). The same author found that the total weed density and biomass were still significantly lower in solarised soil than in the untreated plots also after the harvest of the second crop under greenhouse and field conditions, therefore being a reliable possibility to replace the few chemicals available to manage weeds in conventional lettuce production.

Bàrberi et al. (2009) highlighted that soil solarisation can be combined with hot steaming, as a measure to reduce the use of methyl bromide for soil disinfection. Most of the weed seeds are killed with steam heating the soil from $70-100^{\circ} \mathrm{C}$ to a depth of at least $10 \mathrm{~cm}$, but weeds below this layer may be unaffected and germinate when the soil is disturbed to that depth (Bond et al., 2003). Bàrberi et al. (2009) also mention that although steaming may also kill the beneficial soil microflora, it helps to overcome soil solarisation's limits: viable alternative in Mediterranean and tropical areas, limited use in summer months and occupation of vast areas with plastic films up to 3 months. Alopecurus myosuroides, Fallopia convolvulus and Setaria viridis were the most sensitive species to steaming alone, with about $77 \%$ control efficacy. Additionally, the effect of hot water $\left(85^{\circ}-95^{\circ} \mathrm{C}\right)$ and hot foam on weeds has also been reported as a good control method without affecting crops; the foam is intended to remain on the weeds and prolong the effect of the heat (Bond et al., 2003).

\subsubsection{Flame weeding}

Weeds are killed by flaming due to the intense wave of heat that ruptures the plant cells and desiccates them, thus a foliar contact treatment is required, and any long-term effects depend on the plant recovery and the subsequent weed emergence (Bond et al., 2003). Flaming equipment uses liquefied petroleum gas (propane) and the burners can produce up to $1900^{\circ} \mathrm{C}$ (Knezevic et al., 2011). Flaming can be applied on the whole vegetation or directed to unwanted weeds, with the advantage that burners can be used when soil conditions do not allow mechanical weeding or herbicide resistant species are to be controlled (Bond et al., 2003). Leaf relative water content, growth stage of the weeds and timing of treatment application are influential factors for the efficacy of flaming, according to greenhouse experiments by Knezevic et al. (2011). These authors found that flaming was more effective when conducted on the afternoon between 3 P.M. and 6 P.M. at early growth stages of the plants. However, since flaming does not disturb the soil, some weeds (especially grasses) may escape weed control because their growing point during early growth stages is below the soil surface, thus is protected from the flame (Bond et al., 2003; Knezevic et al., 2011). Furthermore, some crop plants were also affected by the flame, and therefore it is important to apply the treatment as late as possible before the crop emerges (Hansson \& Svensson, 2011). 


\subsubsection{Manual weeding}

Pulling the weeds by hand or weeding with hand tools reaches the desired level of absolute site-specific weed control (Rueda et al., 2010). The major constraints are the low capacity in terms of hectares per hour and the high labour costs per hectare, especially if the weed density is extremely high and other measures fail. For instance, Hansson \& Svensson (2011) found that if flame weeding was used one day too early, it may increase the hand weeding costs by approximately 280 euros per hectare. In a review of hand weeding tools used in Europe some implements are still very effective, e.g. to control deep-rooted grass weeds (Bond et al., 2007). Other tools are available to cut or move soil to cover small weeds, while the operator is standing or kneeling on the surface, such as the draw hoe, swan-necked hoe, onion hoe, collinear hoe, Dutch hoe, Swiss oscillating hoe, stirrup hoe. In developing countries, hand weeding tools may be combined with animal drawn tools to reduce the human labour, increase the area cultivated per hour and become a cheaper option than herbicides (Benzing, 2001).

\subsubsection{Further alternatives to control weeds}

Bond et al. (2003) made a review of other ways to control weeds. Electrocution, an electrical discharge of about 15,000 V, can kill weeds (Blasco et al., 2002), but even at a low weed density of 15 plants $\mathrm{m}^{-2}$, a big amount of energy is required, and therefore it would not be suitable as primary weed control tool. Microwave radiation uses ultra high frequency (UHF) electromagnetic energy at a larger wavelength than light, and this radiation can kill weeds, however this technique is very slow and expensive.

Lasers emit hight amounts of light that can inhibit the plant growth due to the heat generated during absorption, but often do not kill weeds. Heisel et al. (2001); Mathiassen et al. (2006); Nadimi et al. (2009) have demonstrated in experiments with $\mathrm{CO}_{2}$ lasers the possibility to regulate the weed growth centre. However, more research is required to validate the viability for this technology to be usable. Another alternative is biological weed control, through its classical approach (introducing a biocontrol agent, e.g. micro-organism or insects), by inundating a region with a large numbers of biocontrol agent or through a conservative approach where a detailed ecological knowledge is required about the weed and the biocontrol agent. An example of the latter is allelopathy, which is the release of allelochemicals from a plant or a fungal species that is toxic to other plant species.

\section{Site-specific weed management}

Site-specific weed management (SSWM) provides opportunities to reduce the amount of herbicides to a minimum of the required amount (Christensen et al., 2009). Several aspects of the policy in section 1.2 have to be integrated for a successful use of SSWM: items III, V, VI and VIII are addressed directly, and the resulting data sets can further be used for monitoring tasks (II).

Nowadays the application of herbicides is usually done on the field level: the herbicides are selected according to the crop in the field, then a mixture is prepared and uniformly applied to the whole field. A common practice is to estimate the mean weed infestation and use thresholds for the weed species, which are to be considered. The weed density thresholds and occurrence of weed species are used to compose the necessary herbicide mixture. Afterwards this mixture is applied to the field, usually with a sprayer that can regulate the amount of 
herbicide according to the velocity, resulting in a uniform application on the field in terms of a constant amount per area, measured in litres per hectare.

This approach does not take into account the variability of the weed density within the field. Therefore herbicides are used even in weed free parts of the field, where this would not be necessary. Weeds are often found to have an irregular distribution within a field, with high densities in small-scale patches (Dieleman \& Mortensen, 1999; Gerhards \& Christensen, 2003). These irregularities arise from varying numbers of seeds in the soil (the seed bank), and germination probabilities can be different according to the local soil conditions, water availability and several other factors. Some influencing factors are crop-related: the general ability of the crop to suppress weeds and compete for the resources. Local variations of coverage and time of emergence can also arise from irregular sowing densities and depths.

Site-specific weed management (SSWM) addresses the within-field variability explicitly. To be able to change management practices on the sub-field level several prerequisites are necessary. The procedure to implement SSWM includes the following steps:

1. The actual weed infestation/weed pressure has to be assessed within the field. Christensen et al. (2009) identify an automation of the weed mapping component as a missing prerequisite for SSWM. Approaches have been described in the literature to build up such systems, and they will be outlined in section 4.1 .

2. Decisions have to be made for the (local) treatment. Decision components for weed management have been developed to aid farmers and researchers, an overview is given in section 4.2 .

3. The field must be subdivided into management zones, each zone delineating areas of similar treatment.

4. Documentation of the management for further use (section 4.3).

5. Application technology (sprayers) with the ability to vary the treatment is needed (section 4.4) to carry out the treatment plan according to the management zones.

These steps resemble the general workflow cycle in precision agriculture, which have often been visualised as a circle (Srinivasan, 2006, p. 23): starting with data sampling the following steps are data processing, decision making, application and a subsequent control of the effectiveness of the taken actions (e.g. by yield/weed mapping). The introduction of precision farming technology by the farmers still faces some challenges: new technology has to provide benefits, either economically or in terms of a reduced manual work load. The interest to invest in such implements and to change the necessary management decisions, varies between farmers. Reichardt et al. (2009) interviewed farmers (in Germany) regularly about their knowledge and adoption status and found the need for better information, e.g. in education, and that only parts of the farmers are introducing precision technology. The basic instrumentation like GPS and steering aids have the highest uptake rate among farmers. More work has to be done to implement such technology in a user-friendly way and deal with the complexity of the task itself and the many different components, which all have to work together.

\subsection{Sensing weeds}

A prerequisite for a broad introduction of SSWM is the possibility to automatically detect weeds. Manual weed sampling is too expensive in terms of labour, the costs for the working 
hours in the field reduce the economic benefit of the possible savings. The variation of the weed infestation within a field has to be assessed prior to the application (Wiles, 2005).

There are two different cases for the treatment which have to be considered separately: pre-emergence and post-emergence application of herbicides. In the first case the plants are not yet germinated, and herbicides are applied to the soil to prevent germination. It is clear, that in this case there is nothing specific which could be sensed and analysed within the field. An analysis of the seed bank is very labour intensive (Wiles \& Brodahl, 2004; Wiles \& Schweizer, 2002) and involves taking soil samples and analysis of the samples in a laboratory. To achieve this, a lot of manual work has to be carried out, and therefore this approach does not scale to larger areas. On the other hand it is possible to estimate the size and location of seed banks from germination rates, such that historical maps of the weed infestation could be used for a precision application (Christensen \& Heisel, 1998; Williams \& Mortensen, 2000).

For the second case (post-emergence application), weed detection automation has been successfully applied. Brown \& Noble (2005); Singh et al. (2011); Weis \& Sökefeld (2010) review the methods and approaches for an automated weed sampling. There are only a few commercially available sensor systems on the market, which can be used for weed density estimation. WeedSeeker (NTech Industries Inc., Ukiah, CA, USA), Detectspray (North American Pty, Ltd., NSW, Australia, 1995) and Crop Circle (Holland Scientific, Inc., Lincoln, NE) are products, which have been used in research for this task (Andújar et al., 2011; Biller, 1998; Biller et al., 1997; Sui et al., 2008). An additional requirement for the sensing, which is not yet fulfilled by the sensors on the market, is the identification of different weed species to be able to use selective herbicides (Gutjahr \& Gerhards, 2010). This cannot be achieved with the optical technology in the named products, since they only measure values correlating with the general coverage. In crop-free areas, e.g. between the rows or during pre-emergence of the crop, these systems can be used, since from the coverage the biomass of the weed and therefore the infestation can be estimated. With additional, a priori information about the occurring weed species this can be used to generate spraying decisions. Also, if broadband herbicides are to be applied, these sensors provide valuable data. A similar approach is possible with remote sensing data (Thorp \& Tian, 2004).

The full benefit of site-specific weed management can be achieved, if selective herbicides are used on the sub-field level. A reason for this can be found in the heterogeneous distribution of each species: each species can show a different distribution pattern within the field (Gutjahr et al., 2009; Sökefeld, 2010).

Two general approaches for site-specific weed sensing and herbicide application can be distinguished: an 'offline' and 'online' procedure. For the offline approach the two steps —sensing and application — are sequential, which means that the weed infestation is assessed first, then assembled offline to a weed infestation map and an application map and the latter is used in a second step in the field to apply the herbicides (Oebel \& Gerhards, 2006). An example of the offline approach is given in Figures 1 and 2. In a first step the weed infestation situation was acquired manually and with a sensor-system in a maize crop located at the research station of the University of Hohenheim, Ihinger Hof, in Renningen near Stuttgart, Germany (May 2008). Plant coverage measurements are shown as grey values in a grid. From the coverage the patchiness of the weed distribution can already be seen. A more detailed image analysis led to a species discrimination. The latter are depicted as coloured points, measurements without detected weeds are white. The manually identified weed patches for 


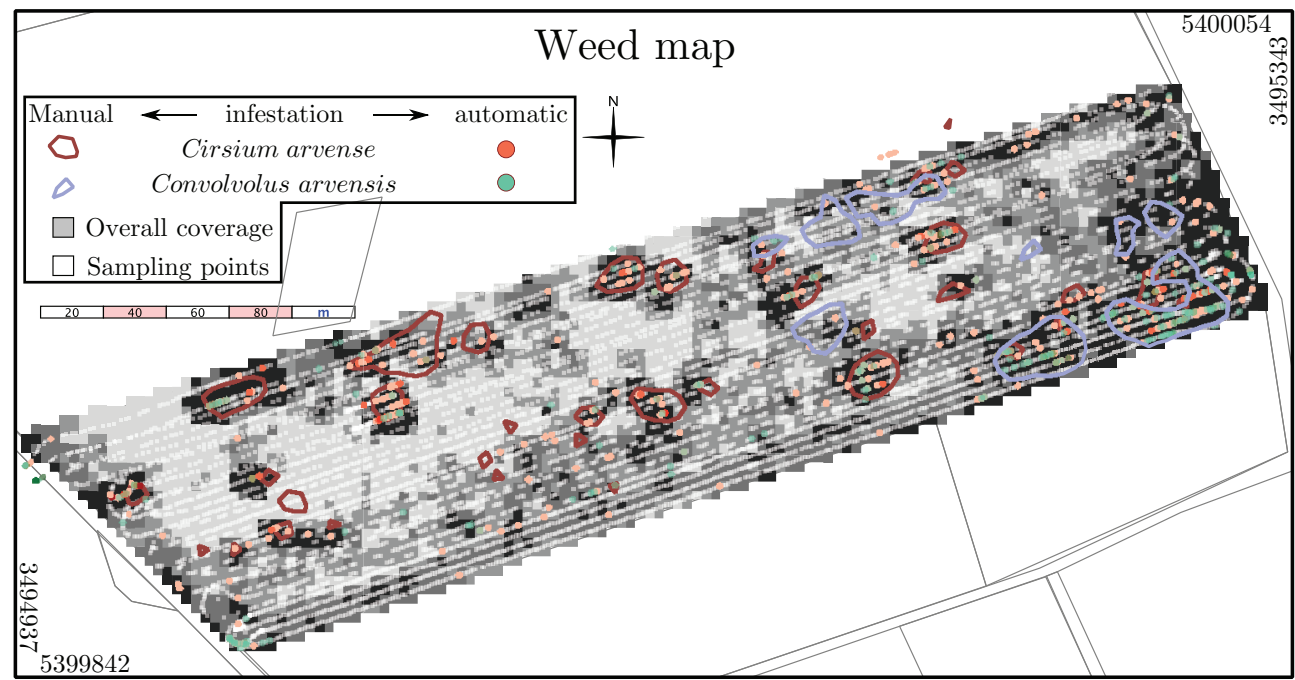

Fig. 1. Weed map, the dots are the results of the automatic weed sampling, the polygons were measured manually. Additionally the overall coverage and sampling points are shown. The coordinates are given in Gauß-Krüger projection (DHDN Zone 3).

two perennial weed species (Cirsium arvense and Convolvulus arvensis) are outlined as polygons and overlaid. Further details of the analysis system for the measurement of these maps can be found in Weis (2010). The information about the weed infestation was then used to create an application map for a site-specific treatment of Cirsium arvense (Fig. 2). The application map contains the management zones, composed as a regular grid of quadratic polygons. For each zone a treatment decision was derived: green zones are to be sprayed, white zones do not need treatment. The comparison with the manually acquired patches shows that the overall decision based on the sensor measurements is suitable for the treatment. Only small patches were missed by the system, mostly due to the sampling distance, since the patches were either between the measured tracks or the measurements did not 'hit' plants in low-infested patches. Due to the zones' structure and singular false positives, a slightly larger area compared to the manual measurements was marked for treatment. Nevertheless only $30 \%$ of the total field area were treated, leading to herbicide savings of $70 \%$.

An online approach combines both steps, integrating the sensing, decision making and application during a single pass (Blasco et al., 2002; Tian, 2002), e.g. with robotic approaches (as described in section 5.1). This can be achieved with smart sensors for the weed detection in combination with a decision and control component on the tractor. Such systems are in development for commercialisation and will give an opportunity for sensor guided applications on a large scale.

\subsection{Decision rules and decision support systems}

The economic weed density threshold is the density at which the costs of an application equal the monetary loss due to the yield decrease caused by the weed infestation. Economic thresholds provide simple rules to decide whether weed control is (economically) justified or not on the field level and thus reduce the herbicide use compared to prophylactic herbicide 


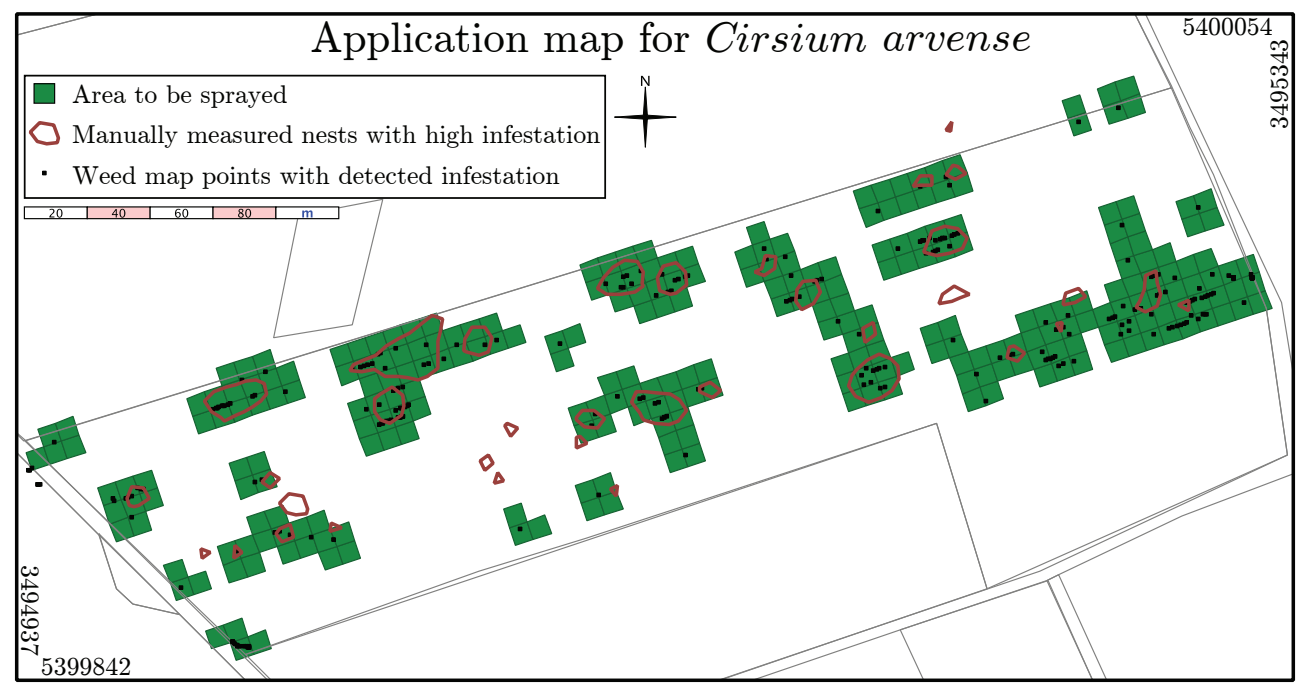

Fig. 2. Application map for Cirsium arvense, generated from the automatically measured weed map in Fig. 1. The weed map values were interpolated to a grid of $6 \times 6 \mathrm{~m}$ with a $3 \mathrm{~m}$ buffer.

applications (Coble \& Mortensen, 1992; Gerowitt \& Heitefuss, 1990). The decision whether to spray or not depends on the average weed infestation of a field, assessed early in the season. The determined thresholds vary in the literature e.g. Gerowitt \& Heitefuss (1990) used threshold values of 20-30, 40-50, 0.1-0.5 m-2 for grass weeds, broadleaved weeds and for cleavers (Galium aparine) respectively in small annual grains. For broadleaved weeds also a threshold of $5-10 \%$ of ground cover was tested (Gerowitt \& Heitefuss, 1990). Economic thresholds have generally not been adjusted to changing prices of grain and herbicides and thus serve merely as a guideline (Gerhards et al., 2011; Gutjahr \& Gerhards, 2010).

In contrast to economic thresholds, Decision Support Systems (DSSs) are more sophisticated decision aids. They are valuable in situations in which the amount of available information (e.g. crop growth stage, weed species, weather conditions, herbicide spectrum, their economic and ecological properties and implications) is too large for intuitive decision-making (Mir \& Quadri, 2009). For uniform field herbicide applications, many DSSs have been presented in research journals and several are also implemented and available as web-based, desktop and / or pocket (on-site usage) solution (Bennett et al., 2003; Rydahl, 2003). Frequently required inputs for DSSs are the grown crop, its competitive ability (e.g. growth stage, vigour), weed species, weed densities, weed growth stages, herbicide and application costs, the expected price for the crop and the expected yield without weed competition (Gutjahr \& Gerhards, 2010).

Wiles et al. (1996) distinguished between efficacy-based and population-based DSSs for weed control. The former provide herbicide recommendations and in some cases recommendations for the optimal herbicide dose for the actual weed infestation of a field. An integral part of these DSS are databases storing information about herbicide performance under various conditions (crop, weed species, growth stage etc.), as reported by Christensen et al. (2009). Examples of this type of DSSs are SELOMA (Stigliani \& Cosimo, 1993) or Crop Protection 
Online (Rydahl, 2003). In addition, population-based DSS incorporate information about weed biology, ecology and management through deterministic models (Christensen et al., 2009; Wiles et al., 1996). Examples are HERB (Wilkerson et al., 1991) or GESTINF (Berti \& Zanin, 1997). Gutjahr \& Gerhards (2010) provide a review of various DSSs in weed control. DSSs for weed control have considerably evolved and are still evolving from quite simple models using only few aspects relevant to weed control to DSSs that integrate more aspects as optimum dose rates, weather conditions, considerations regarding the environment and the problem of herbicide resistance development (Rydahl et al., 2008). For example, the DSS Weed Manager integrates two time scales, a within single season and an overall scale for several years in rotation perspectives. A multi-stage heuristic decision model for the in season decision model and for the over several years rotation perspective they used stochastic dynamic programming in this DSS (Parsons et al., 2009). Furthermore, DSSs for weed control vary in the number of crops and weed species included, some are only designed for a few crops and a limited number of weeds. Others are functional for the main crops and weeds at national or regional level (Rydahl et al., 2008). One drawback of DSSs is that they are seldom transparent to the users and that the models do not allow the user to interact or change neither the algorithms nor the model parameters. Furthermore, in countries, in which DSSs have already been implemented and are available to farmers, less than $3 \%$ of the farmers were using them (Rydahl et al., 2008).

As stated before weeds occur in patches and therefore patch spraying, i.e. spraying only restricted to areas with weed densities high enough to cause economic yield loss, should allow considerable herbicide savings. Gerhards \& Oebel (2006) could achieve herbicide savings from $6-81 \%$ for herbicides against broad-leaved weeds and $20-79 \%$ for herbicides against grass weeds in cereals. In trials carried out by Wiles (2009), 34\% of the field areas could be left untreated in average. It is important to notice that these potential savings depend on the actual weed distribution and the employed decision algorithms.

Only few DSSs for patch spraying have been presented so far (Gutjahr \& Gerhards, 2010). The system DAPS (Decision Algorithm for Patch Spraying) was developed for barley (Hordeum vulgare L.) and winter wheat (Triticum aestivum L.) and was tested in a 5-year field trial by Christensen et al. (2003). The model consists of three main components: i) a competition model, which uses the density equivalent model approach presented by Berti \& Zanin (1994). ii) a herbicide dose-response model and iii) an algorithm which derives the economically optimal herbicide dose for a given weed infestation (Christensen et al., 2003). In the field trial this model for patch spraying was compared with PC-Plant Protection, a control and a so called mean DAPS in a completely randomized design with 10 replicates. For the DAPS each plot consisted of 6 management zones of $12 \times 12 \mathrm{~m}$. In each managment zone weed density was determined in circular sample of $0.25 \mathrm{~m}^{2}$. The field trial indicated no significant differences in yield, however significant herbicide savings of DAPS compared with PC-Plant Protection (Christensen et al., 2003). HPS-online has been suggested by Gutjahr \& Gerhards (2010), but it has not been implemented yet. Weed cover of single weed species or weed groups, determined by bi-spectral cameras and classification algorithms, and economical basis data serve as input. Parameters of yield loss functions for single weed species, and parameters of dose-response curves for the respective weed and herbicide combinations are used to derive a yield gain function in dependence of the applied dose. Using the costs of weed control and the expected price for the crop, the optimal dose can be determined for each management zone. In addition, it is planned to allow the farmer to adjust the system according to current conditions, 
e.g. crop status or weather conditions (Gutjahr \& Gerhards, 2010). For this suggested model robustness/predictability of yield loss functions has to be researched, since they can differ between locations and years. In addition most yield loss functions have been determined with weed density as explanatory variable. Furthermore dose-response parameters are not all available, and dose-response curves have been determined mainly in the greenhouse and the transferability of such results to field conditions is difficult.

Generally, for site-specific spraying the term DSS can be misleading, as the algorithms should not suggest or recommend the herbicide or the control needed, instead they take the decision whether to spray or not, or to spray more or less for the respective management zone. This is especially the case for an on-line approach, when the herbicides or the herbicide mixture have been chosen in advance, the sprayer is already loaded and the decision to spray or not to spray has to be taken in real-time at the sprayer's regular speed. The use of GPS and the geo-referenced documentation of spraying decisions would open the possibility to provide the farmer with a log file or a map highlighting locations in the field, where the system had identified patches of weeds which could not be fully controlled by the loaded herbicide, rising the awareness of the farmers to potential problems and to allow him to take actions. In addition, the decision algorithms should only require little computing time.

Concluding, DSSs support farmers' decision making in weed control and can optimize weed control economically and minimize the negative environmental effects of weed control. However, the use and adoption of DSSs by farmers and consultants have to be brought forward. In addition, more field data has to be gathered to support and calibrate decision algorithms and calculation models of DSSs (Rydahl et al., 2008). For site-specific weed control, the two presented examples and the above mentioned results of field trials show the potential for considerable herbicide savings if site-specific spraying is adopted by farmers. Ecological benefits of patch spraying can be considerable. On one hand the amount of applied herbicide is reduced as herbicides are only applied in field areas, where herbicides are needed. On the other hand, in field areas where no herbicides are applied, flora and fauna can establish without disturbance, enhancing the overall biodiversity (Timmermann et al., 2003). Neither DAPS nor HPS-online is available to farmers (yet), but launches of commercial products integrating automated weed sensing, decision algorithms and application technology are to be expected soon.

\subsection{Data handling}

As seen before, a lot of data is needed for precise treatments: measurement data acquired in the field or by remote sensing, application maps, yield maps and soil maps, all of them with a spatial component. For decision support not only such spatial data, but also the weather conditions, active ingredients of pesticides, timing information, regulation rules, equipment information, farm data and a lot more have their role and need to be integrated for the final decision about the optimal management.

In precision farming, geographic positions have to be acquired during the treatments to identify the areas which have already been treated. This way the documentation of the taken actions helps to avoid overlaps directly during the treatment. If prescriptions maps were prepared, then a terminal software needs to look up the actual position in the map and use its information additionally for the control decision. Therefore geographic information systems (GIS), GPS positioning and terminals to control the equipment play an important 
role in precision agriculture. Some farm management information systems already include the possiblity to store certain geodata, although most of them do not target and handle precision farming data explicitly. Partial solutions exist to create application maps that can be transferred to the farm equipment for applications in the field.

Storage of geodata itself is only one aspect of the necessary data handling, additionally metadata is needed to describe the data sets itself, answering at least the following questions: who acquired the data, how, when and which equipment was used, what was the goal and usage perspective and how accurate is the data, which preprocessing steps have been applied? This way the data sets can be found and understood later, which is necessary for further analysis steps, if they are based on this data. If for example an economic analysis of the long-term strategy is performed, then all data sets acquired during the time frame considered can be relevant inputs.

By coupling locally acquired data sets and external sources, e.g. weather data and pest prediction service data, new application fields are supported. The complexity of DSSs for integrated pest/weed management can be tackled by a suitable modularisation into components. These components do not necessarily need to be run on one system or created and implemented by one manufacturer, if suitable interfaces allow the exchange of data between them. By interconnecting components the expertise of different fields and sources can be joined. A service-oriented architecture based on web-enabled services provides the technical framework for the implementation of system components that can be joined together as needed. Services like recommendations based on the data and functionality of such components are an option for the portfolio of consultants and as such should be developed in cooperation with the experts in the field.

The standardisation of data and services may find technological solutions soon, as they are the topic of recent research efforts (Nash et al., 2010). Difficulties arise mainly from semantical barriers, which prevent the correct interpretation of data and its meaning in different contexts. Farm manangement information systems (FMIS) should include such standards and thus can add functionality in a modular manner. As FMIS are used by the end-users (farmers), they provide the tool for integration of expert systems, which can be created and maintained as modular solutions. Such standardisation may require an important contribution from researchers and the willingness to implement them in commercial products, and therefore might need considerable time before becoming usable. The introduction of the ISOBUS standard, defining interfaces for interoperation of machinery components, into agriculture needed roughly a decade until all relevant manufacturers were providing functional interfaces. Such a standard on the other hand allows the development of new applications with less effort (Iftikhar \& Pedersen, 2011). AgroXML is another proposed standard for farm management data exchange (Schmitz et al., 2009), and has successfully been applied to farming tasks supporting a distributed system structure (Steinberger et al., 2009). If the regulations were available in a formal, machine-readable rule format, then operations can be planned and checked according to these regulations. Authorities and researchers as well as FMIS providers need to work together to reach this goal and provide useful tools for the end-users. The necessary prerequisites have been defined (Nash et al., 2011; Nikkilä et al., 2010) and proof-of-concept solutions were developed to show the feasibility of the approach in the European project FutureFarm (Nikkilä et al., 2010). Especially for the weed population modeling the WeedML standard has been proposed (Holst, 2010), fostering coooperation and 
exchange between researchers in this field. Systems integrating this technology can become an integral part for the decision support of farmers.

\subsection{Application technology for weed management}

The application technology for chemical weed management has seen advances in the last decade, leading to more precise application of herbicides in the field and thus reducing the amount of herbicides applied. The equipment to apply herbicides to the field plays an important role for an optimized treatment.

One concern for an optimum treatment quality is the reduction of drift. In windy weather conditions the drift effect can lead to an uneven treatment, because the spray liquid moves from the envisaged position and can stack up in neighbouring areas. The resulting, unwanted variation within the field can on the one hand lead to poor weed control due to lower amounts, on the other hand damage the crop in vulnerable growth stages and also the environment in areas with higher amounts. It can also lead to pollution of non-target areas outside of the field, often in shelter-belts where the wind velocity is reduced. The drift can especially be a problem for targeted omission of sensitive areas, e.g near water or biotopes. To comply with restrictions, optimal drift reduction is one crucial prerequisite. It can be achieved by selection and calibration of the equipment, and naturally by applying under good weather conditions (no wind). One way to reduce the drift is the selection of nozzles with larger orifice size producing larger droplets or special drift-reducing nozzles, which for example incorporate air into the spray droplets. The droplet size is also dependent on the spray pressure and additives that increase spray viscosity. Bigger droplets are not as susceptible to wind as smaller ones. The selection of the right nozzle is not only dependent on the drift effect, but also relying on other circumstances. Smaller droplets can have advantages for the uptake efficiency by the plant, since the more homogeneous wetting raises the probability for absorption into the leaf. Adjuvants additionally can be used to intensify the contact of the droplets to the leaf surface and aid the uptake through the epidermis.

Nowadays most sprayers are able to control the amount of herbicides to a uniform level by feedback control systems. By pressure variation they control the amount according to the driving speed, assuring constant amounts of spray liquid per area unit.

\subsubsection{Variable rate technology}

For a precise treatment and variation of the herbicide application within a field, sprayer technology has to be able to adapt the rates according to a spraying plan. Variable rate technology (VRT) became available in the last decade and entered the market for precision applications (Sökefeld, 2010).

A basic variation of the amounts can be realised by switching on and off the whole boom or parts of it. In the latter case the whole boom width is divided into parts which can be controlled independently of each other. The parts can be sections of fixed length or down to the single nozzle with an individual nozzle control. With such systems it is possible to avoid overlaps, since the nozzles or sections can be switched off in areas which have already been treated. They can also be used to leave out no-treatment zones and fulfil distance requirements (e.g. near running waters). 
Technically the flow control and thereby the amount of a herbicide mixture can be achieved by pressure variation. If the pressure is lowered centrally, then the amounts on the whole boom width are reduced. There are upper and lower limits for flow rate, depending on the pressure operation interval of the nozzles. Pressures outside this interval lead to insufficient droplet sizes. Other systems use solenoid valves, which are directly integrated at each nozzle and allow to control the flow based on an electromechanical principle. Mixing the fluid with air in the nozzles can reduce the flow down to the half. Varying orifices in the nozzles are another way to control the output, this can be achieved either by a moving, steerable component within each nozzle or by combining several nozzles into one holder and switching between them. The presented technology can vary the amount of a prepared herbicide mixture.

If the herbicide mixture itself should be varied within the field, additional techniques have to be used. Either each herbicide gets mixed beforehand into several tanks and sprayed independently of each other, or the mixing takes place on the sprayer. A late mixing has the advantage to lower the amount of mixture within the whole system, which is favourable for the cleaning procedure and the minimised amount of remainders. In the extreme case herbicides are mixed near/in the nozzles into fresh water by direct injection systems (Schulze-Lammers \& Vondricka, 2010). Because in this case the mixing takes place under pressure, the resulting problems have to be addressed: small amounts of liquid and varying viscosity have to be mixed into relatively large amounts of water, such that the resulting fluid is homogeneous before reaching the nozzle (Vondřička, 2007).

There are sprayers appearing on the market explicitly targeting precision farming applications, implementing such techniques. The Pre-Mix-System (Amazone) has a water tank and an additional tank with a preliminary mixture and can therefore vary the concentration down to zero during the operation by mixing these two components. The VarioInject system (Lechler) is a direct injection system, which can be mounted in the rear of the sprayer and mix the raw herbicide ingredients on demand with water. This way mixture remaining can be reduced to a minimum and only the herbicide actually applied to the field is used.

\section{Herbicide-tolerant crops}

Since their introduction in 1996 herbicide-resistant crops have been planted on a rapidly increasing areas, amounting worldwide to 83.6 Mha in 2009 and even more if crops with stacked traits are considered (Gianessi, 2008; James, 2009). In general, herbicide-resistance has been the dominant trait in biotech crops. In the process, glyphosate [N-(phosphonomethyl)glycine]-resistant soybean (Glycine max (L.) Merr.), maize (Zea mays L.), canola (Brassica napus L.) and cotton (Gossypium hirsutum L.) were most important (Duke \& Powles, 2009; James, 2009; Owen, 2008). The major herbicide-resistant crop growing countries are USA, Brazil, Argentina, India and Canada (James, 2009). In Europe, the cultivation of herbicide-resistant crops has mainly been restricted to field trials dudue to public concerns and opposition (Davison \& Bertheau, 2007; Kleter et al., 2008).

Despite the controversial debate in Europe, herbicide-resistant crops have several advantages. The use of herbicide-resistant crops, such as glyphosate- and glufosinate-resistant ones, broadens the spectrum of controlled weeds and provides new mode of actions to be used in-crop. This is especially important to control weed population resistant against other herbicides. In addition these herbicides are rather environmentally friendly and are easily 
degraded in soil (Knezevic \& Cassman, 2003) and due to their broad spectrum they can replace several herbicides which would be used alternatively (Duke, 2005).

Gianessi (2005) calculated considerable savings in the amount of applied herbicide in the US agriculture due to glyphosate-resistant crops, whereas Benbrook (2001) found an increase in herbicide use in herbicide-resistant crops compared to conventional crops. Duke (2005) stated that more studies suggested a decrease in herbicide use in herbicide-resistant crops or a comparable amount of herbicide use than an increase. However, if farmers rely merely and consequently on this tool of herbicide-resistant crops, increased tolerance and resistance of weeds can spread rapidly and shifts within weed communities will occur readily (Knezevic \& Cassman, 2003). In glyphosate-resistant soybean for example, Ipomoea and Commelina species as winter annuals are becoming much more common and problematic. The easiest way to control these more frequently occurring weeds, is to add tank-mix partners to glyphosate, which again results in higher use of herbicides (Culpepper, 2006). In addition there is the risk of gene escape i.e. transfer of resistant genes to other plant species, which can result in very difficultly controllable weeds and high herbicide inputs to control them (Knezevic \& Cassman, 2003). One trend is to combine several tolerance genes in herbicide-resistant crops, this will decrease the single selection pressure of a distinct herbicide (Green, 2009), but also increase again the use of herbicides.

The sound use of herbicide-resistant crops can provide a tool to reduce herbicide use and allowing the use of more environmentally friendly herbicides. However, a smart combination with other IWM management tools is a prerequisite to sustain these opportunities.

\subsection{Robotic weeding}

Robots were introduced into production systems a long time ago and have found their place for tasks, which are repetitive and therefore error-prone or are carried out in dangerous environmental conditions. A robot can be defined as a machine, which is able to sense its environment, analyse the situation and decide for an action according to a task specification. Actuation is then initiated with a control component ensuring the correct operation. A certain degree of 'intelligence' is needed to react on the changing surrounding and act accordingly. Therefore often artificial intelligence techniques are implemented in this field. Such technology found its place mainly in controlled environments (e.g. industrial production lines) and has proven to conduct repetitive tasks in an efficient manner. The extension of the operation to agricultural fields is on the way, and some machinery already implement part of the robotic properties (Blackmore et al., 2007). The security of the operation of unmanned vehicles is one of the obstacles, which has to be addressed. Human supervision and interaction nowadays is still necessary, the automation of subtasks on the other hand steadily develops. Many implements for field operation already include sensing, steering and control systems for their unguided operation. In agriculture, these implements can be modular: tractors implement parts of robotic navigation, sensors can be mounted to sense the status of the crop or soil and terminals are used to make decisions and control implements according to their abilities (Blasco et al., 2002). Robots integrate all of the aforementioned technologies (sensing, decision support, actuators), but also require additional techniques for the navigation. Combinations of such technology therefore can be regarded as robots, e.g. the proposed weed sensing and technology already works to a large extent without human intervention, since the decision can be based on sensor data, and the decision and actuation (spraying) are automated and do not require human interaction. Tractors with 
auto-steering guided by GPS already reduce the amount of work for the driver, such that the driver can focus on other tasks. The future of robots in agricultural production systems can either advance in the automation and control of large machines or the development of smaller machines for special local operations. Robotic weeding is an approach to automate the labour intensive task of manual weed scouting and/or weeding. It has the potential to be carried out not only on the canopy or local (row) scale, but operate on the plant level. Autonomous machines could take over parts of the task, either for the autonomous creation of weed maps or the weed management on small scales. Operation times of robots are an argument for their introduction: tedious and time-consuming tasks can be done by robots in a 24/7 manner. If implements are available that target single plants, like micro sprayers (Midtiby et al., 2011) or hoes (Melander, 2006), then the operation of these can be carried out on a robot. The treatment of single plants limits the driving speed, as opposed to the development towards faster and larger implements with higher field area capacity. This can be counteracted by the use of multiple, smaller robots, which in turn are more flexible in their use (Blackmore et al., 2007). It is likely that parts of the machinery undergo development with robotic technology and the final solution will be a combination of task specific implements, which can be combined individually, creating task specific robotic automation as needed. The sensor developments and decision components researched lead the way and their integration will lead to new possibilities for the management.

Some problems still need to be tackled, before an introduction into wider practice will take place: the security of operation, energy constraints on smaller machines. Support and supervision of such technology on the other hand open new fields for businesses.

\section{Conclusion}

Weeds still are the cause of high yield losses, and alternative measures for weed control are required, because of the rising problems with herbicide residues in the environment and food. The alternative weeding methods without herbicides described in this chapter present a high potential to successfully compete with herbicide treatments. For instance, weed harrowing or a combination of flaming with mechanical tools, has shown an increase in crop yields due to the achieved weed control, up to a similar or even higher level than that obtained with chemical control. Considering these methods within a balanced approach such as a integrated weed management plan, there is a good chance to fulfil the political framework, at least in Europe, to prefer non-chemical weed control methods and to move towards the integrated pest management. However, it requires some risk acceptance and training efforts by the farmers to accomplish a good decision making plan. Existing sensors to assess the complex crop- weed- and soil variability contribute to reduce the use of herbicides towards a site-specific weed management approach, because then they could be only used on a sub-field level. Site-specific weeding also profits from the opportunities of information systems, data handling and decision support systems. Especially the latter is relevant, as DSS can optimize weed control economically and from an environmental point of view. In addition, this technology will allow monitoring the management success over a larger time-scale. In Europe, herbicide-resistant crops may gain some attention in the future, at least on a research level, for their potential to reduce herbicide application or to use only active ingredients which harm the environment less. However, public concern and opposition will still be a big barrier to overcome. More research is necessary to validate the performance and risks of such crops, and then training and public information is needed, as not only 
the farmers need to know about the pros and cons, but also the consumers. Finally, robotic weeding seems a promising technology to become successful in industrialized countries to reduce chemical weed control, once accurate and robust methods for automatic and real-time weed discrimination are developed. Nevertheless, once again expert knowledge is the most essential part for decision making technology, and there is still much to investigate, in order to tackle the constraints like security of the operator, energy consumption, time of operation and purchase cost of a robot weeding system. But even without highly engineered equipment considerable amounts of herbicides can be saved. The right management decisions have to be taken and multiple measures for weed control should be introduced into the existing production systems and their well-established practices.

\section{References}

Andújar, D., Ángela Ribeiro, Fernández-Quintanilla, C. \& Dorado, J. (2011). Accuracy and feasibility of optoelectronic sensors for weed mapping in wide row crops, Sensors 11(3): 2304-2318.

URL: http://www.mdpi.com/1424-8220/11/3/2304/

Benbrook, C. (2001). Do GM crops mean less pesticide use?, Pesticide outlook 12(5): 204-207.

Bennett, A. C., Price, A. J., Sturgill, M. C., Buol, G. S. \& G., W. G. (2003). HADSS, pocket HERB, and webHADSS: Decision aids for field crops, Weed Technology 17: 412-420.

Benzing, A. (2001). Agricultura Orgánica: Fundamentos para la Región Andina [Organic agriculture: principles for the Andean regions], Neckar-Verlag, Villingen-Schwenningen.

Berti, A. \& Zanin, G. (1994). Density equivalent: a method for forecasting yield loss caused by mixed weed populations, Weed Research 34: 327-332.

Berti, A. \& Zanin, G. (1997). Gestinf: a decision model for post-emergence weed management in soybean (Glycine max (1.) merr.), Crop Protection 16: 109-116.

Biller, R. H. (1998). Reduced input of herbicides by use of optoelectronic sensors, Journal of Agricultural Engineering Research 71: 357-362.

URL: http://www.sciencedirect.com/science/article/B6WH1-45J55FB-7/2/43cd9c341a6ae32 Od4ee5b88c65966fb

Biller, R., Hollstein, A. \& Sommer, C. (1997). Precision application of herbicides by use of optoelectronic sensors, Precision Agriculture pp. 451-.

Blackmore, B., Griepentrog, H., Fountas, S. \& Gemtos, T. (2007). A specification for an autonomous crop production mechanization system, Agricultural Engineering International: the CIGR Ejournal IX(PM 06 032): 1-24.

URL: http://www.cigrjournal.org/index.php/Ejounral/article/view/900/894

Blackshaw, R. E., Moyer, J. R., Doram, R. C., \& Boswell, A. L. (2001). Yellow sweetclover, green manure, and its residues effectively suppress weeds during fallow, Weed Science 49(3): 406-413.

Blasco, J., Aleixos, N., Roger, J. M., Rabatel, G. \& Moltó, E. (2002). Ae-automation and emerging technologies: Robotic weed control using machine vision, Biosystems Engineering 83: 149-157.

URL: http://www.sciencedirect.com/science/article/B6WXV-474G449-2/1/77aae51c283a3e8 e193f2f0a7fgfd8aa

Bond, W., Turner, R. \& Davies, G. (2007). A review of mechanical weed control, Technical report, HDRA, Ryton Organic Gardens, Coventry, CV8 3LG, UK.

URL: http://www.gardenorganic.org.uk/organicweeds 
Bond, W., Turner, R. \& Grundy, A. (2003). A review of non-chemical weed management, Technical report, HDRA, Ryton Organic Gardens, Coventry, CV8 3LG, UK HRI, Wellesbourne, Warwick, CV35 9EF, UK.

URL: http://www.organicweeds.org.uk

Bàrberi, P., Moonen, A. C., Peruzzi, A., Fontanelli, M. \& Raffaelli, M. (2009). Weed suppression by soil steaming in combination with activating compounds, Weed Research 49(1): 55-66.

URL: http://onlinelibrary.wiley.com/doi/10.1111/j.1365-3180.2008.00653.x/abstract

Brown, R. \& Noble, S. (2005). Site-specific weed management: sensing requirements - what do we need to see?, Weed Science 53(2): 252-258.

URL: $h$ ttp://dx.doi.org/10.1614\%2FWS-04-068R1

Candido, V., D'Addabbo, T., Miccolis, V. \& Castronuovo, D. (2011). Weed control and yield response of soil solarization with different plastic films in lettuce, Scientia Horticulturae 130(3): 491-497.

URL: http://www.sciencedirect.com/science/article/pii/S0304423811004079

Christensen, S. \& Heisel, T. (1998). Patch spraying using historical, manual and real-time monitoring of weeds in cereals, Zeitschrift für Pflanzenkrankheiten und Pflanzenschutz Sonderheft XVI: 257-263.

Christensen, S., Heisel, T., Walter, A. M. \& Graglia, E. (2003). A decision algorithm for patch spraying, Weed Research 43: 276-284.

Christensen, S., Søgaard, H., Kudsk, P., Nørremark, M., Lund, I., Nadimi, E. \& Jørgensen, R. (2009). Site-specific weed control technologies, Weed Research 49(3): 233-241.

Cimen, I., Turgay, B. \& Pirin, V. (2010). Effect of solarization and vesicular arbuscular mychorrizal on weed density and yield of lettuce (Lactuca sativa 1.) in autumn season, African Journal of Biotechnology 9(24): 3520-3526.

URL: http://www.scopus.com/inward/record.url?eid=2-s2.0-77953939652EpartnerID=40 $\mathcal{E} m d 5=a 41 a d e 3 c 7 f 567239 a a 3 c 65 f d 4 e 6 c f 9 c c$

Coble, H. D. \& Mortensen, D. A. (1992). The trheshold concept and its application to weed science, Weed Technology 6: 191-195.

Corre-Hellou, G., Dibet, A., Hauggaard-Nielsen, H., Crozat, Y., Gooding, M., Ambus, P., Dahlmann, C., von Fragstein, P., Pristeri, A., Monti, M. \& Jensen, E. (2011). The competitive ability of pea-barley intercrops against weeds and the interactions with crop productivity and soil $\mathrm{n}$ availability, Field Crops Research 122(3): 264-272.

URL: $h t t p: / / w w w . s c i e n c e d i r e c t . c o m / s c i e n c e / a r t i c l e / p i i / S 037842901100116 X$

Culpepper, A. S. (2006). Glyphosate-induced weed shifts, weed technology 20(277-281).

Davison, J. \& Bertheau, Y. (2007). EU regulations on the traceability and detection of GMOs: difficulties in interpretation, implementation and compliance, $C A B$ reviews: Perspectives in agriculture, veterinary science, nutrition and natural resources 77.

Dieleman, J. \& Mortensen, D. (1999). Characterizing the spatial pattern of Abutilon theophrasti seedling patches, Weed Research 39: 455-467.

Duke, S. O. (2005). Taking stock of herbicide-resistant crops ten years after introduction, Pest management science 61: 211-218.

Duke, S. \& Powles, S. B. (2009). Glyphosate-resistant crops and weeds: now and in the future, Agbioforum 12: 346-357.

ENDURE (2008). Integrated weed management (iwm) case study - report on field studies, literature review, general conclusions and recommendations and future iwm research, Deliverable DR1.6, ENDURE - European Network for Durable 
Exploitation of crop protection strategies. Project number: 031499. URL: http://www.endure-network.eu/content/download/5616/43701/file/ENDURE_DR1.6.pdf

ENDURE (2009). Presentation of DEXiPM arable crops A qualitative multi-criteria model for the assessment of the sustainability of pest management systems, Deliverable DR2.14a, ENDURE - European Network for Durable Exploitation of crop protection strategies. Project number: 031499. URL: http://www.endure-network.eu/content/ download/5616/43701/file/ENDURE_DR1.6.pdf

European Parliament \& Council of the EU (2009). Directive 2009/128/EC of the European Parliament and of the Council of 21st October 2009 establishing a framework for Community action to achieve the sustainable use of pesticides (Text with EEA relevance), Official Journal of the European Union L 309: 71-86. 24.11.2009. URL: http:// eur-lex.europa.eu/LexUriServ/LexUriServ.do? uri=OJ:L:2009:309:0071:0086:EN:PDF

Gerhards, R. \& Christensen, S. (2003). Real-time weed detection, decision making and patch spraying in maize, sugar beet, winter wheat and winter barley, Weed Research 43(6): 385-392.

URL: $h$ ttp://dx.doi.org/10.1046/j.1365-3180.2003.00349.x

Gerhards, R., Gutjahr, C., Weis, M., Keller, M., Sökefeld, M., Möhring, J. \& Piepho, H. (2011). Using precision farming technology to quantify yield effects due to weed competition and herbicide application, Weed Research . to appear.

Gerhards, R. \& Oebel, H. (2006). Practical experiences with a system for site-specific weed control in arable crops using real-time image analysis and GPS-controlled patch spraying, Weed Research 46(3): 185-193.

Gerowitt, B. \& Heitefuss, R. (1990). Weed economic thresholds in the F. R. Germany, Crop Protection 9: 323-331.

Gianessi, L. P. (2005). Economic and herbicide use impacts of glyphosate-resistant crops, Pest management science pp. 241-245.

Gianessi, L. P. (2008). Review economic impacts of glyphosate-resistant crops, Pest management science 64: 346-352.

Green, J. M. (2009). Evolution of glyphosate-resistant crop technology, Weed Science (57): 108-117.

Gutjahr, C. \& Gerhards, R. (2010). Precision Crop Protection - the Challenge and Use of Heterogeneity, in Oerke et al. (2010), 1 edn, chapter Decision rules for site-specific weed management, pp. 223-239.

URL: http://springer.com/978-90-481-9276-2

Gutjahr, C., Weis, M., Sökefeld, M. \& Gerhards, R. (2009). Influence of site specific herbicide application on the economic threshold of the chemical weed control, in A. Bregt, S. Wolfert, J. Wien \& C. Lokhorst (eds), EFITA conference '09, EFITA (European Federation for Information Technology in Agriculture), Wageningen Academic Publishers, Wageningen, Netherlands, pp. 557-565. Only available on CD-rom (PDF-file) - Papers presented at the 7th EFITA conference, Joint International Agricultural Conference, 6.-8. July.

URL: http://www.efita.net/apps/accesbase/bindocload.asp? $d=6549 \mathcal{E} t=0 \mathcal{E}$ identobj=4K9sKV1 $z \mathcal{E} u i d=57305290 \mathcal{E}$ sid $=57 \mathcal{E} i d k=1$

Hansson, D. \& Svensson, S.-E. (2011). Effect of flame weeding at different time intervals before crop emergence, in D. C. Cloutier (ed.), Proceedings 9th EWRS Workshop on Physical and Cultural Weed Control, 28-30 March 2011, Samsun, Turkey, p. 65. 
Heisel, T., Schou, J., Christensen, S. \& Andreasen, C. (2001). Cutting weeds with a CO2 laser, Weed Research 41: 19-29.

URL: $h t t p: / / d x$. doi.org/10.1111/j.1365-3180.2001.00212.x

Holst, N. (2010). WeedML: a tool for collaborative weed demographic modeling, Weed Science 58(4): 497-502.

URL: http://www.bioone.org/doi/abs/10.1614/WS-D-09-00013.1

Iftikhar, N. \& Pedersen, T. B. (2011). Flexible exchange of farming device data, Computers and Electronics in Agriculture 75(1): 52-63.

URL: http://www.sciencedirect.com/science/article/pii/S0168169910001894

James, C. (2009). Global status of commercialized Biotech/GM crops: 2009, Technical Report 41, International service for the acquisition of agri-biotech applications, ISAAA: Ithaca, NY. URL: http://www.isaaa.org/resources/publications/briefs/41/download/isaaa-brief41-2009.pdf

Jensen, R. K., Rasmussen, J. \& Melander, B. (2004). Selectivity of weed harrowing in lupin, Weed Research 44(4): 245-253.

URL: http://www.blackwell-synergy.com/doi/abs/10.1111/j.1365-3180.2004.00396.x

Jones, R., Cacho, O. \& Sinden, J. (2006). The importance of seasonal variability and tactical responses to risk on estimating the economic benefits of integrated weed management, Agricultural Economics 35(3): 245-256.

URL: http://onlinelibrary.wiley.com/doi/10.1111/j.1574-0862.2006.00159.x/abstract

Kleter, G. A., Harris, C., Stephenson, G. \& Unsworth, J. (2008). Review comparison of herbicide regimes and the associated potential environmental effects of glyphosate-resistant crops versus what they replace in Europe, Pest management science 64: 479-488.

Knezevic, S. Z. \& Cassman, K. G. (2003). Use of herbicide-tolerant crops as a component of an integrated weed management program, Crop management. URL: http://www. plantmanagementnetwork.org/pub/cm/management/2003/htc/Knezevic.pdf

Knezevic, S. Z., Ulloa, S. M., Datta, A., Arkebauer, T., Bruening, C. \& Gogos, G. (2011). Weed control and crop tolerance to propane flaming as influenced by time of day, in D. C. Cloutier (ed.), Proceedings 9th EWRS Workshop on Physical and Cultural Weed Control, 28-30 March 2011, pp. 66-78.

Kurstjens, D. A. G. \& Kropff, M. J. (2001). The impact of uprooting and soil-covering on the effectiveness of weed harrowing, Weed Research 41(3): 211-228.

URL: $h t t p: / / d x$. doi.org/10.1046/j.1365-3180.2001.00233.x

Kurstjens, D. A. G. \& Perdok, U. D. (2000). The selective soil covering mechanism of weed harrows on sandy soil, The selective soil covering mechanism of weed harrows on sandy soil 55(3-4): 193-206.

URL: http://www.sciencedirect.com/science/article/B6TC6-40NMSHJ-7/2/670aad35b93496 3ae0cff06c93bde62c

Llewellyn, R. \& Pannell, D. (2009). Managing the herbicide resource: an evaluation on extension for herbicide-resistant weed management, AgBioForum 12(3/4): 358-369.

URL: http://www.agbioforum.org/v12n34/v12n34a11-llewellyn.htm

Mathiassen, S. K., Bak, T., Christensen, S. \& Kudsk, P. (2006). The effect of laser treatment as a weed control method, Biosystems Engineering 95: 497-505.

URL: http://www.sciencedirect.com/science/article/B6WXV-4M57H8K-1/1/d694981c000e8 944e8f69701dc0d4de5 
Melander, B. (2006). Current achievements and future directions of physical weed control in europe, AFPP 3rd International conference on non-chemical crop protection methods, number 9998, Danish Institute of Agricultural Sciences, Department of Integrated Pest Management, Research Centre Flakkebjerg, Orgprints, Lille, France, pp. 49-58. URL: http://orgprints.org/9998/

Melander, B., Rasmussen, I. A. \& Bàrberi, P. (2005). Integrating physical and cultural methods of weed control - examples from european research, Weed Science 53(3): 369-381.

URL: http://dx.doi.org/10.1614/WS-04-136R

Midtiby, H. S., Mathiassen, S. K., Andersson, K. J. \& Jørgensen, R. N. (2011). Performance evaluation of a crop/weed discriminating microsprayer, Computers and Electronics in Agriculture 77: 35-40.

URL: http://dl.acm.org/citation.cfm?id=1994680

Mir, S. A. \& Quadri, S. M. K. (2009). Climate change, intercropping, pest control and beneficial microorgansims, Vol. 2 of sustainable agriculture reviews, Springer, Dordrecht, Heidelberg, London, New York, chapter Decision support systems: concepts, progress and issues - a review, pp. 373-399.

Nadimi, E. S., Andersson, K. J., Jørgensen, R. N., Maagaard, J., Mathiassen, S. \& Christensen, S. (2009). Designing, modeling and controlling a novel autonomous laser weeding system, 7th World Congress on Computers in Agriculture Conference Proceedings, number 711P0409e, ASABE - American Society of Agricultural and Biological Engineers, St. Joseph, MI. 22-24 June 2009, Reno, Nevada (electronic only).

URL: http://asae.frymulti.com/abstract.asp?aid $=29077$

Nash, E., Nikkilä, R., Pesonen, L., Oetzel, K., Mayer, W., Seilonen, I., Kaivosoja, J., Bill, R., Fountas, S. \& Sørensen, C. (2010). Machine readable encoding for definitions of agricultural crop production and farm management standards, Deliverable 4.1.1, FutureFarm. Integration of Farm Management Information Systems to support real-time management decisions and compliance of management standards Knowledge Management in the FMIS of Tomorrow.

URL: http://futurefarm.eu/node/183

Nash, E., Wiebensohn, J., Nikkilä, R., Vatsanidou, A., Fountas, S. \& Bill, R. (2011). Towards automated compliance checking based on a formal representation of agricultural production standards, Computers and Electronics in Agriculture 78(1): 28-37.

URL: http://www.sciencedirect.com/science/article/pii/S0168169911001244

Nikkilä, R., Wiebensohn, J., Nash, E. \& Seilonen, I. (2010). Integration of farm management information systems to support real-time management decisions and compliance of management standards, Deliverable D4.4, FutureFarm. WP 4 topic: Knowledge Management in the FMIS of Tomorrow.

URL: http://www.futurefarm.eu/system/files/FFD4.4_Proof_Of_Concept_Final.pdf

Nikkilä, R., Seilonen, I. \& Koskinen, K. (2010). Software architecture for farm management information systems in precision agriculture, Computers and Electronics in Agriculture 70(2): 328-336.

URL: http://www.sciencedirect.com/science/article/B6T5M-4XMC000-1/2/54b46b3c8aa2a9 ee60d022eb392b017a

Oebel, H. \& Gerhards, R. (2006). Kameragesteuerte Unkrautbekämpfung - eine Verfahrenstechnik für die Praxis, Journal of Plant Diseases and Protection Special Issue XX: 181-187.

URL: http://www.jpdp-online.com/Artikel.dll/04-Oebel_MTAyNDIy.PDF 
Oerke, E. (2006). Crop losses to pests, Journal of Agricultural Science 144(1): 31-43.

Oerke, E.-C., Gerhards, R., Menz, G. \& Sikora, R. A. (eds) (2010). Precision Crop Protection the Challenge and Use of Heterogeneity, 1 edn, Springer Verlag, Dordrecht, Heidelberg, London, New York.

URL: $h$ ttp://springer.com/978-90-481-9276-2

Owen, M. (2008). Review weed species shifts in glyphosate-resistant crops, Pest management science 64: 377-387.

URL: http://www.ask-force.org/web/HerbizideTol/Owen-Weed-Species-Shifts-2008.pdf

Parsons, D. J., Benjamin, L. R., Clarke, J., Ginsburg, D., Mayes, A., Milne, A. E. \& Wilkinson, D. J. (2009). Weed manager - a model-based decision support system for weed management in arable crops, Comput. Electron. Agric. 65(2): 155-167.

URL: http://portal.acm.org/citation.cfm?id=1501021.1501071

Reichardt, M., Jürgens, C., Klöble, U., Hüter, J. \& Moser, K. (2009). Dissemination of precision farming in Germany: acceptance, adoption, obstacles, knowledge transfer and training activities, Precision Agriculture 10(6): 525-545.

URL: http://www.springerlink.com/content/d64qk22343jl1386/

Rueda-Ayala, V., Rasmussen, J., Fournaise, N. \& Gerhards, R. (2011). Influence of timing and intensity of post-emergence weed harrowing in winter wheat on weed control, crop recovery and crop yield, Weed Research . in press.

Rueda, V., Rasmussen, J. \& Gerhards, R. (2010). Precision Crop Protection - the Challenge and Use of Heterogeneity, in Oerke et al. (2010), 1 edn, chapter Mechanical weed control, pp. 279-294.

URL: http://springer.com/978-90-481-9276-2

Rueegg, W. T., Quadranti, M. \& Zoschke, A. (2007). Herbicide research and development: challenges and opportunities, Weed Research 47: 271-275.

Rydahl, P. (2003). A web-based decision support system for integrated management of weeds in cereals and sugarbeet, Bulletin OEPP/EPPO Bulletin 33: 455-460.

Rydahl, P., Berti, A. \& Munier-Jolain, N. (2008). O.24 - decision support systems (dss) for weed control in europe - state-of-the art and identification of 'best parts' for unification on an european level, ENDURE. Papers presented at the ENDURE International Conference 2008, diversifying crop protection, La Grande-Motte, France, 12-15 October 2008. URL: http://www.endure-network.eu/international_conference_2008/proceedings/ tuesday_october_14

Schmitz, M., Martini, D., Kunisch, M. \& Mösinger, H.-J. (2009). agroXML enabling standardized, platform-independent internet data exchange in farm management information systems, Springer US, Boston, MA, pp. 463-468.

URL: http://www.springerlink.com/content/kr4755744634g63r/

Schulze-Lammers, P. \& Vondricka, J. (2010). Precision Crop Protection - the Challenge and Use of Heterogeneity, in Oerke et al. (2010), 1 edn, chapter Direct Injection Sprayer, pp. 295-310.

URL: $h$ ttp://springer.com/978-90-481-9276-2

Singh, K., Agrawal, K. \& Bora, G. C. (2011). Advanced techniques for weed and crop identification for site specific weed management, Biosystems Engineering in Press. URL: http://www.sciencedirect.com/science/article/B6WXV-52DB334-1/2/d827016de58dd $4 a 8 c 65 f b 4 e f 4 a 9 d f e 71$ 
Sökefeld, M. (2010). Precision Crop Protection - the Challenge and Use of Heterogeneity, in Oerke et al. (2010), 1 edn, chapter Variable rate technology for herbicide application, pp. 335-347.

URL: http://springer.com/978-90-481-9276-2

Srinivasan, A. (2006). Handbook of precision agriculture: principles and applications, Food Products Press, an imprint of The Haworth Press, Inc., Binghamton, NY.

URL: http://www.haworthpress.com/store/product.asp?sku=5627

Steinberger, G., Rothmund, M. \& Auernhammer, H. (2009). Mobile farm equipment as a data source in an agricultural service architecture, Computers and Electronics in Agriculture 65(2): 238-246.

URL: $h$ ttp://portal.acm.org/citation.cfm?id=1501079

Stigliani, L. \& Cosimo, R. (1993). SELOMA: Expert system for weed management in herbicide-intensive crops, Weed Technology 7: 550-559.

Storrie, A., Jones, R., Monjardino, M., Preston, C., Stewart, V., Walker, S., Hashem, A., Simpfendorfer, S., Holding, D., Widderick, M., Lemerle, D., Walsh, M., Bowcher, A., Evans, C., Moore, J. \& D'Emden, F. (2006). Integrated weed management in australian cropping systems - a training resource for farm advisors, Technical report, CRC for Australian Weed Management, University of Adelaide, PMB 1, Glen Osmond, SA 5064 Australia. November.

URL: $\quad$ http://www.grdc.com.au/director/events/linkpages/weedlinks\#Integrated Weed Management manual

Sui, R., Thomasson, J. A., Hanks, J. \& Wooten, J. (2008). Ground-based sensing system for weed mapping in cotton, Computers and Electronics in Agriculture 60: 31-38.

URL: http://www.sciencedirect.com/science/article/B6T5M-4P8R7BS-1/1/ac4921ce458fb93 $1 f 3 f 9 b a 2 c b 9 c 7 c b e 6$

Swanton, C. J., Mahoney, K. J., Chandler, K. \& Gulden, R. H. (2008). Integrated weed management: Knowledge-based weed management systems, Weed Science 56(1): 168-172.

Thorp, K. \& Tian, L. (2004). A review on remote sensing of weeds in agriculture, Precision Agriculture 5(5): 477-508.

URL: $\quad$ http://openurl.ingenta.com/content? genre=articleEissn $=1385-2256 \mathcal{E}$ volume $=5$ Eissue $=5$ Espage $=477$ Eepage $=508$

Tian, L. (2002). Development of a sensor-based precision herbicide application system, Computers and Electronics in Agriculture 36: 133-149.

Timmermann, C., Gerhards, R. \& Kühbauch, W. (2003). The economic impact of the site-specific weed control, Precision Agriculture 4(3): 249-260.

URL: $h t t p: / / d x$.doi.org/10.1023/A:1024988022674

van der Weide, Y., Bleeker, P. O., Achten, V. T. J. M., Lotz, L. A. P., Folgegerg, F. \& Melander, B. (2008). Innovation in mechanical weed control in crop rows, Weed Research 48(3): 215-224.

URL: $h t t p: / / d x$. doi.org/10.1111/j.1365-3180.2008.00629.x

Vondřička, J. (2007). Study on the process of direct nozzle injection for real-time site-specific pesticide application, $\mathrm{PhD}$ thesis, Rheinische Friedrich-Wilhelms-Universität, Bonn. Forschungsbericht Agrartechnik des Arbeitskreises Forschung und Lehre der Max-Eyth-Gesellschaft Agrartechnik im VDI (VDI-MEG).

URL: http://www.landtechnik.uni-bonn.de/ifl_research/pp_15/vondricka_dissertation.pdf 
Weis, M. (2010). An image analysis and classification system for automatic weed species identification in different crops for precision weed management, $\mathrm{PhD}$ thesis, Institute for Phytomedicine, Department of Weed Science, University of Hohenheim, Stuttgart, Germany.

URL: http://opus.ub.uni-hohenheim.de/volltexte/2010/519/

Weis, M. \& Sökefeld, M. (2010). Precision Crop Protection - the Challenge and Use of Heterogeneity, in Oerke et al. (2010), 1 edn, chapter Detection and identification of weeds, pp. 119-134.

URL: http://springer.com/978-90-481-9276-2

Wiles, L. (2009). Beyond patch spraying: site-specific weed management with several herbicides, Precision Agriculture 10(3): 277-290.

URL: http://dx.doi.org/10.1007/s11119-008-9097-6

Wiles, L. \& Brodahl, M. (2004). Exploratory data analysis to identify factors influencing spatial distributions of weed seed banks, Weed Science 52: 936-947.

URL: http://dx.doi.org/10.1614\%2FWS-03-068R

Wiles, L. J. (2005). Sampling to make maps for site-specific weed management, Weed Science 53: 228-235.

URL: http://dx.doi.org/10.1614\%2FWS-04-057R1

Wiles, L., King, R., Schweizer, E., Lybecker, D. \& Swinton, S. (1996). Gwm: general weed management model, Agricultural Systems 50: 355-376.

Wiles, L. \& Schweizer, E. (2002). Spatial dependence of weed seed banks and strategies for sampling, Weed Science 50(5): 595-606.

URL: $h t t p: / / d x$.doi.org/10.1614\%2F0043-17453ASDOWSB\%5D2.0.CO\%3B2

Wilkerson, G. G., Modena, S. A. \& Coble, H. D. (1991). Herb: Decision model for postemergence weed control in soybean, Agronomy Journal 83: 413-417.

URL: http://agron.scijournals.org/cgi/content/abstract/agrojnl;83/2/413

Williams, M. \& Mortensen, D. (2000). Crop/weed outcomes from site-specific and uniform soil-applied herbicide applications, Precision Agriculture 2(4): 377-388.

Zornbach, W. (2011). Leitlinien Integrierter Pflanzenschutz, slides, online. Fachgespräch über die aktuelle Situation bei der Entwicklung von Leitlinien zum integrierten Pflanzenschutz.

URL: $h t t p: / / n a p . j k i . b u n d . d e /$ index.php? menuid $=76 \mathcal{E}$ downloadid $=168 \mathcal{E}$ reporeid $=0$ 


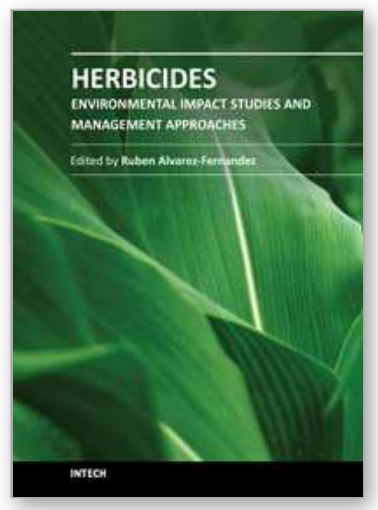

\section{Herbicides - Environmental Impact Studies and Management Approaches}

Edited by Dr. Ruben Alvarez-Fernandez

ISBN 978-953-307-892-2

Hard cover, 248 pages

Publisher InTech

Published online 20, January, 2012

Published in print edition January, 2012

Weeds severely affect crop quality and yield. Therefore, successful farming relies on their control by coordinated management approaches. Among these, chemical herbicides are of key importance. Their development and commercialization began in the 1940's and they allowed for a qualitative increase in crop yield and quality when it was most needed. This book blends review chapters with scientific studies, creating an overview of some the current trends in the field of herbicides. Included are environmental studies on their toxicity and impact on natural populations, methods to reduce herbicide inputs and therefore overall non-target toxicity, and the use of bioherbicides as natural alternatives.

\section{How to reference}

In order to correctly reference this scholarly work, feel free to copy and paste the following:

MartinWeis, Martina Keller and Victor Rueda Ayala (2012). Herbicide Reduction Methods, Herbicides -

Environmental Impact Studies and Management Approaches, Dr. Ruben Alvarez-Fernandez (Ed.), ISBN: 978953-307-892-2, InTech, Available from: http://www.intechopen.com/books/herbicides-environmental-impactstudies-and-management-approaches/herbicide-reduction-methods

\section{INTECH}

open science | open minds

\section{InTech Europe}

University Campus STeP Ri

Slavka Krautzeka 83/A

51000 Rijeka, Croatia

Phone: +385 (51) 770447

Fax: +385 (51) 686166

www.intechopen.com

\section{InTech China}

Unit 405, Office Block, Hotel Equatorial Shanghai

No.65, Yan An Road (West), Shanghai, 200040, China

中国上海市延安西路65号上海国际贵都大饭店办公楼405单元

Phone: +86-21-62489820

Fax: +86-21-62489821 
(C) 2012 The Author(s). Licensee IntechOpen. This is an open access article distributed under the terms of the Creative Commons Attribution 3.0 License, which permits unrestricted use, distribution, and reproduction in any medium, provided the original work is properly cited. 